\title{
Effect of antimicrobial photodynamic therapy on the treatment of peri-implantitis: narrative review
}

\author{
Juliana Bertoldi Franco ${ }^{1,2}$, Mônica Ghislaine Oliveira Alves ${ }^{3,4} \wedge$ \\ ${ }^{1}$ Department of Dentistry, Auxiliary Hospital of Suzano and Central Institute, Clinical Hospital of Medical School of the University of São Paulo, \\ São Paulo, Brazil; ${ }^{2}$ Department of Stomatology, School of Dentistry, University of São Paulo, São Paulo, Brazil; ${ }^{3}$ Technology Research Center (NPT), \\ Universidade Mogi das Cruzes, Mogi das Cruzes, Brazil; ${ }^{4}$ School of Medicine, Anhembi Morumbi University, São José dos Campos, Brazil \\ Contributions: (I) Conception and design: JB Franco; (II) Administrative support: MGO Alves; (III) Provision of study materials or patients: Both \\ authors; (IV) Collection and assembly of data: Both authors; (V) Data analysis and interpretation: Both authors; (VI) Manuscript writing: Both \\ authors; (VII) Final approval of manuscript: Both authors. \\ Correspondence to: Mônica Ghislaine Oliveira Alves. 200 Dr. Cândido Xavier de Almeida Souza Avenue, Mogi das Cruzes, SP 08780-911, Brazil. \\ Email: mgoliveiraalves@gmail.com.
}

Background and Objective: The greatest challenge of implantology is the maintenance of dental implants, with peri-implantitis being the main cause of implant loss. Studies highlight the importance of dental biofilm control, reduction of the inflammatory process in the peri-implant mucosa and decontamination of the implant surface, as well as the need for surgical intervention. Recently, low-level laser therapy (LLLT) has been introduced in different dental specialties, especially those related to oral mucosa lesions and the treatment of periodontal disease. The combination of LLLT and a photosensitizer dye promotes antimicrobial activity (aPDT) and may be used as a noninvasive treatment of peri-implantitis. The objective of this study was to conduct a literature review on the use of antimicrobial photodynamic therapy (aPDT) in the treatment of peri-implantitis.

Methods: The search was carried out in the PubMed, using the keywords: "Peri-implantitis", "low-level laser therapy", "antimicrobial photodynamic therapy". The inclusion criteria were: original articles and systematic reviews published until April 12, 2021, in English, that discussed use of aPDT in the treatment of peri-implantitis.

Key Content and Findings: aPDT is the combination of LLLT with a photosensitizer dye, being a noninvasive technique used as an adjunct to surgical periodontal treatment. aPDT can improve the response of bone and soft tissues, reducing inflammation and painful symptoms. And this technique can be the treatment of choice for patients who do not want to be submitted to conventional surgical treatment or for patients with systemic conditions that contraindicate surgical management.

Conclusions: aPDT can be considered an adjunct to mechanical (scaling) and surgical (grafts) treatments in peri-implantitis since it appears to be effective in reducing the bacterial load and has potential as therapy. Additionally, clinical and radiographic follow-up of the patient is important to monitor the improvement of gingival inflammation, implant mobility, and the interruption of bone loss.

Keywords: Antimicrobial photodynamic therapy (aPDT); low-level laser therapy (LLLT); peri-implant diseases

Received: 23 April 2021; Accepted: 21 June 2021; Published: 10 June 2022.

doi: $10.21037 /$ fomm-21-53

View this article at: https://dx.doi.org/10.21037/fomm-21-53

^ ORCID: Juliana Bertoldi Franco, 0000-0001-7787-4062; Mônica Ghislaine Oliveira Alves, 0000-0002-3411-9443. 


\section{Introduction}

Laser therapy began to be used in medicine in the 1960s, with the first studies being published in ophthalmology (1). Despite its widespread use today, low-level laser therapy (LLLT) was introduced in dentistry in the 1990s, with application in the area of oral surgery, in postoperative care after tooth extraction, in cases of paresthesia after surgical dental procedures, and to reduce dentinal sensitivity (1).

After many years, the benefits of LLLT are now better understood. This therapy began to be used in different areas of dentistry because of its main characteristics, including the stimulation of edema absorption and cell repair and the promotion of analgesia. LLLT was first used particularly in the care of cancer patients who developed radio- and/or chemotherapy-induced oral mucositis during their treatment. This treatment promoted pain relief in these patients, which significantly decreased the use of opioid analgesics and accelerated the wound healing process, reducing hospitalizations and the interruption of antineoplastic treatment (2-8).

In addition to these indications, LLLT is currently applied to oral lesions such as recurrent aphthous ulcers resulting from vesiculobullous diseases and traumatic chemical injuries, among others $(9,10)$. Besides the main known biological principles of LLLT, the combination with dyes such as methylene blue and toluidine blue promotes antimicrobial activity, a procedure known as antimicrobial photodynamic therapy (aPDT). The latter is widely used for the treatment of opportunistic infections (oral candidiasis, herpes simplex, and cytomegalovirus), oral bone necrosis, osteomyelitis and periodontal diseases, the disinfection of root canals and dental implant surfaces, and in cases of peri-implantitis (11). We present the following article in accordance with the Narrative Review reporting checklist (available at https://fomm.amegroups. com/article/view/10.21037/fomm-21-53/rc).

\section{Objective}

The objective of this study was to conduct a literature review on the use of aPDT in the treatment of peri-implantitis.

\section{Methods}

The search was carried out in the PubMed, using the keywords: "Peri-implantitis", "low-level laser therapy", "antimicrobial photodynamic therapy". The inclusion criteria were: original articles and systematic reviews published until 2021, in English, that discussed use of aPDT in the treatment of peri-implantitis (Table 1).

\section{Discussion}

\section{Peri-implantitis}

Biological complications of dental implants can be caused by the accumulation of dental biofilms around the implant in cases of peri-implant mucositis and peri-implantitis. Cases not associated with biofilms such as gingival recession and gingival hyperplasia are caused by occlusal trauma or by inadequate placement of the prosthetic crown (12). The diagnosis must be made by clinical examination, with attention to the presence of bleeding on probing, increased probing depth and suppuration, and by radiographic examination for the observation of bone loss $(12,13)$.

It is important to distinguish peri-implant mucositis from the condition of peri-implantitis. The diagnostic criteria of peri-implant mucositis include the presence of bleeding and/or suppuration on gentle probing with or without increased probing depth compared to previous examinations and the absence of bone loss beyond crestal bone-level changes resulting from initial bone remodeling. The criteria for the diagnosis of peri-implantitis are the presence of bleeding and/or suppuration on gentle probing; increased probing depth compared to previous examinations, and the presence of bone loss beyond crestal bone-level changes resulting from initial bone remodeling. In the absence of previous examinations, the diagnosis of peri-implantitis can be made considering the following criteria: presence of bleeding and/or suppuration on gentle probing; probing depth $>6 \mathrm{~mm}$, and bone level $>3 \mathrm{~mm}$ apical of the most coronal portion of the intraosseous part of the implant (12).

Routine examinations for clinical and radiographic assessment of dental implants are indicated to ensure mechanical and biological maintenance of the implant. The early detection of these alterations permits timely intervention and improves the prognosis of the implant $(12,13)$.

Factors that influence the treatment of peri-implantitis include the texture of the implant surface, morphology of the bone defect, the bone graft material used, exposure of the membrane, and changes in the reactivity of the titanium oxide surface during the decontamination procedure $(12,13)$.

Several therapies are available for biofilm control and decontamination of the peri-implant region, including chlorhexidine, scaling of the implant, surgical treatment, 
Table 1 The search strategy summary

\begin{tabular}{ll}
\hline Items & Specification \\
\hline Date of search (specified to date, month and year) & April 12, 2021 \\
Databases and other sources searched & PubMed \\
Search terms used & "Peri-implantitis", "Low-level laser therapy", "Antimicrobial photodynamic therapy" \\
Timeframe & Published until April 12, 2021 \\
Inclusion and exclusion criteria & Original articles and systematic reviews; English; Articles the discussed use of aPDT \\
Selection process & in peri-implantitis treatment \\
Any additional considerations, if applicable & This review was designed and conducted by JBF and MGOA \\
\hline
\end{tabular}

LLLT [carbon dioxide $\left(\mathrm{CO}_{2}\right)$, neodymium-doped yttrium aluminum garnet (Nd:YAG), erbium-doped yttrium aluminum garnet (Er:YAG) and erbium, chromiumdoped:yttrium, scandium, gallium, garnet (Er,Cr:YSGG)], and the current use of aPDT (14). Surgical treatment can result in marginal soft tissue recession, compromising esthetics. It therefore seems to be important to develop therapies that can interrupt the progression of inflammation without causing mucosal recession. The use of aPDT has been shown to be effective in the treatment of periodontitis and may be a great ally in the treatment of peri-implantitis and the prevention of marginal bone loss $(12,14)$.

\section{Photobiomodulation and aPDT}

Antimicrobial PDT is used as an adjunct to surgical periodontal treatment because of its antimicrobial potential resulting from the stimulation of a photosensitizer by LLLT, which would eliminate periodontopathogenic bacteria (Porphyromonas gingivalis, Prevotella intermedia, Tannerella forsythia, Treponema denticola, and Aggregatibacter actinomycetemcomitans) (15). Lopez et al. (2020) studied the efficacy of aPDT against multibacterial colonization of dental implant surfaces and observed a significant reduction of bacterial load, with a mean reduction of $99.3 \%$ in total bacterial load (16).

Different types of aPDT exist. The most common is the combination of LLLT with a photosensitizer dye, for example, methylene blue or toluidine blue. Specific aPDT devices are available such as HELBO ${ }^{\circledR}$ (TheraLite Laser, HELBO 3D Pocket Probe; Photodynamic Systems GmbH), which operates at a wavelength of $660 \mathrm{~nm}$ and a power density of $100 \mathrm{~mW}$ and uses the dye phenothiazine chloride (13).

Deppe et al. (2013) studied 16 patients with a total of
18 implants divided into two groups: 10 implants exhibited moderate bone loss of up to $5 \mathrm{~mm}$ (group 1) and 8 implants were associated with bone loss of 5 to $8 \mathrm{~mm}$ (group 2). The authors applied aPDT using the HELBO system to all implants, with follow-up times of 2 weeks, 3 months and 6 months. The bleeding on probing index, probing depth, distance from the implant shoulder to gingival margin, and presence of clinical mobility were evaluated. At 3-month assessment, improvement was observed in bleeding after probing and dental implant mobility. After 6 months, the improved conditions persisted in group 1, while group 2 exhibited an increase in bone resorption and mobility. The authors concluded that aPDT can interrupt bone resorption in moderate peri-implant defects but not in severe defects. However, marginal tissue recession occurred in both groups at the end of the study (11).

Marotti et al. (2013) investigated in vitro the disinfection of 60 implants with chlorhexidine, LLLT (GaAlAs lowlevel diode laser; Twin Laser Flex, MM Optics, São Carlos, Brazil; wavelength of $660 \mathrm{~nm}$ ) and aPDT (LLLT and $0.01 \%$ methylene blue) compared to a control group not submitted to disinfection and observed better results when chlorhexidine and aPDT were used (14).

In a systematic review on the advantages of LLLT and aPDT in the treatment of periodontal disease and peri-implantitis, Tamura et al. (2016) found that these treatments improve the response of bone and soft tissues, reducing inflammation and painful symptoms. The authors highlighted that, despite the vast literature on the topic, more in-depth studies are needed (15).

Alqahtani et al. (2019) compared the efficacy of mechanical debridement with and without adjunctive aPDT in the treatment of peri-implantitis between smokers and non-smokers. The authors observed that the combination of mechanical debridement and aPDT is effective and 
emphasized the importance of routine oral hygiene for the success of this therapy (17). Likewise, Javed et al. (2017) concluded that the combination of these therapies is more effective than mechanical debridement alone (18).

In their systematic review, Chambrone et al. (2018) found limited evidence of the benefits of combining surgical intervention and aPDT for the treatment of periodontitis and peri-implantitis, with few studies reporting improvements over 3 months, and that well-defined clinical protocols are scarce. The authors highlighted the importance of aPDT in patients with systemic conditions that contraindicate surgical management. The authors included 26 randomized controlled trials, in which 24 studied aggressive or chronic periodontitis and only 2 studied peri-implantitis (Romeo et al. 2016; Bombeccari et al. 2013). Romeo et al. (2016) demonstrated effectiveness in reducing clinical indices and bacterial load at sites affected by periimplantitis of aPDT, highlighting that the aPDT act as a coadjutant in the treatment of peri-implantitis if associated with mechanical (scaling) and surgical (grafts) treatments in order to control peri-implant disease. Bombeccari et al. (2013) concluded that aPDT seems to reduce distinctly the clinical signs of preimplant inflammation, resulting in a significant reduction of the bleeding scores and inflammatory exudates with respect to the conventional surgical approach $(13,19,20)$.

According to Albaker et al. (2018), aPDT has advantages such as a lower risk of bacterial resistance, suppression of the oral microbiota at the application site and absence of systemic harmful effects; in addition, this therapy does not cause damage at the site of application. The authors highlighted the methodological heterogeneity of the studies conducted in the areas of periodontics and implantology using LLLT and aPDT; however, the treatments were found to be beneficial, improving inflammation and the immunological status of tissues (21).

Deeb et al. (2018) studied mechanical debridement combined with systemic antibiotic therapy and aPDT and concluded that aPDT as an adjunct to mechanical debridement was as effective as adjunctive systemic antimicrobial therapy but with additional benefits in the reduction of bleeding scores (22).

Therefore, LLLT is a technology that was recently introduced into dentistry and that is mainly used for the treatment of oral mucosa lesions. Its combination with a photosensitizer promotes antimicrobial activity and is frequently used in the treatment of opportunistic infections (11). Antimicrobial PDT is widely used in the treatment of periodontal diseases, with good results. Since peri-implantitis is very similar to periodontal disease, many authors began to study possible treatments with LLLT and aPDT $(11-14,21,23)$.

Peri-implantitis negatively affects the survival of dental implants. Several methods for its treatment are available, including surgical techniques, decontamination with antimicrobials, curettage of bone defects and, recently, LLLT and aPDT (11-14,21,23). Patients prefer noninvasive and less painful methods, even if the results are uncertain. There is a vast literature on this subject, with reports of satisfactory results regarding the use of LLLT and aPDT; however, the followup times are short and the study designs are heterogeneous, generating confusion in the protocol used $(13,21,23)$.

Noninvasive techniques can be the treatment of choice for patients who do not want to be submitted to conventional surgical treatment or for patients with systemic conditions that contraindicate surgical management. The advantage of aPDT is that the technique is noninvasive, does not require anesthesia, and is not associated with postoperative pain (13).

\section{Conclusions}

In conclusion, aPDT can be considered an adjunct to mechanical (scaling) and surgical (grafts) treatments in peri-implantitis (19) since it appears to be effective in reducing the bacterial load and has potential as therapy (24). Multiple sessions of aPDT are more effective in reducing inflammation than a single session (25). Additionally, aPDT seems to be an alternative to antibiotics in the treatment of peri-implantitis (26). Clinical and radiographic followup of the patient is important to monitor the improvement of gingival inflammation, implant mobility, and the interruption of bone loss $(13,14,21,23)$.

\section{Acknowledgments}

We would like to thank Kerstin Markendorf for language editing.

Funding: None.

\section{Footnote}

Provenance and Peer Review: This article was commissioned by the Guest Editor (Mario Pérez-Sayáns) for the series "Marginal Bone Loss in Dental Implants: Factors Affecting and How to Prevent It" published in Frontiers of Oral and Maxillofacial Medicine. The article has undergone external peer review. 
Reporting Checklist: The authors have completed the Narrative Review reporting checklist. Available at https:// fomm.amegroups.com/article/view/10.21037/fomm-21-53/ $\mathrm{rc}$

Peer Review File: Available at https://fomm.amegroups.com/ article/view/10.21037/fomm-21-53/prf

Conflicts of Interest: All authors have completed the ICMJE uniform disclosure form (available at https://fomm. amegroups.com/article/view/10.21037/fomm-21-53/coif). The series "Marginal Bone Loss in Dental Implants: Factors Affecting and How to Prevent It" was commissioned by the editorial office without any funding or sponsorship. The authors have no other conflicts of interest to declare.

Ethical Statement: The authors are accountable for all aspects of the work in ensuring that questions related to the accuracy or integrity of any part of the work are appropriately investigated and resolved.

Open Access Statement: This is an Open Access article distributed in accordance with the Creative Commons Attribution-NonCommercial-NoDerivs 4.0 International License (CC BY-NC-ND 4.0), which permits the noncommercial replication and distribution of the article with the strict proviso that no changes or edits are made and the original work is properly cited (including links to both the formal publication through the relevant DOI and the license). See: https://creativecommons.org/licenses/by-nc-nd/4.0/.

\section{References}

1. Campbell CJ, Noyori KS, Rittler MC, et al. Intraocular temperature changes produced by laser coagulation. Acta Ophthalmol Suppl 1963;SUPPL76:22-31.

2. Fernando S, Hill CM, Walker R. A randomised double blind comparative study of low level laser therapy following surgical extraction of lower third molar teeth. $\mathrm{Br}$ J Oral Maxillofac Surg 1993;31:170-2.

3. Gerschman JA, Ruben J, Gebart-Eaglemont J. Low level laser therapy for dentinal tooth hypersensitivity. Aust Dent J 1994;39:353-7.

4. Khullar SM, Brodin P, Barkvoll P, et al. Preliminary study of low-level laser for treatment of long-standing sensory aberrations in the inferior alveolar nerve. J Oral Maxillofac Surg 1996;54:2-8.

5. Walsh LJ. The current status of low level laser therapy in dentistry. Part 1. Soft tissue applications. Aust Dent J 1997;42:247-54.

6. Walsh LJ. The current status of low level laser therapy in dentistry. Part 2. Hard tissue applications. Aust Dent J 1997;42:302-6.

7. Zanin T, Zanin F, Carvalhosa AA, et al. Use of 660-nm diode laser in the prevention and treatment of human oral mucositis induced by radiotherapy and chemotherapy. Photomed Laser Surg 2010;28:233-7.

8. Bensadoun RJ, Franquin JC, Ciais G, et al. Low-energy $\mathrm{He} / \mathrm{Ne}$ laser in the prevention of radiation-induced mucositis. A multicenter phase III randomized study in patients with head and neck cancer. Support Care Cancer 1999;7:244-52.

9. Vale FA, Moreira MS, de Almeida FC, et al. Low-level laser therapy in the treatment of recurrent aphthous ulcers: a systematic review. ScientificWorldJournal 2015;2015:150412.

10. Jajarm HH, Falaki F, Mahdavi O. A comparative pilot study of low intensity laser versus topical corticosteroids in the treatment of erosive-atrophic oral lichen planus. Photomed Laser Surg 2011;29:421-5.

11. Deppe H, Mücke T, Wagenpfeil S, et al. Nonsurgical antimicrobial photodynamic therapy in moderate vs severe peri-implant defects: a clinical pilot study. Quintessence Int 2013;44:609-18.

12. Hirooka H, Renvert S. Diagnosis of Periimplant Disease. Implant Dent 2019;28:144-9.

13. Chambrone L, Wang HL, Romanos GE. Antimicrobial photodynamic therapy for the treatment of periodontitis and peri-implantitis: An American Academy of Periodontology best evidence review. J Periodontol 2018;89:783-803.

14. Marotti J, Tortamano P, Cai S, et al. Decontamination of dental implant surfaces by means of photodynamic therapy. Lasers Med Sci 2013;28:303-9.

15. Tamura R, Miwa T, Shimizu K, et al. Giant Cell Tumor of the Skull: Review of the Literature. J Neurol Surg A Cent Eur Neurosurg 2016;77:239-46.

16. Lopez MA, Passarelli PC, Marra M, et al. Antimicrobial efficacy of photodynamic therapy (PDT) in periodontitis and peri-implantitis: A systematic review. J Biol Regul Homeost Agents 2020;34:59-65. Technology in Medicine.

17. Alqahtani F, Alqhtani N, Alkhtani F, et al. Efficacy of mechanical debridement with and without adjunct antimicrobial photodynamic therapy in the treatment of peri-implantitis among moderate cigarette-smokers and waterpipe-users. Photodiagnosis Photodyn Ther 
2019;28:153-8.

18. Javed F, BinShabaib MS, Alharthi SS, et al. Role of mechanical curettage with and without adjunct antimicrobial photodynamic therapy in the treatment of peri-implant mucositis in cigarette smokers: A randomized controlled clinical trial. Photodiagnosis Photodyn Ther 2017;18:331-4.

19. Romeo U, Nardi GM, Libotte F, et al. The Antimicrobial Photodynamic Therapy in the Treatment of PeriImplantitis. Int J Dent 2016;2016:7692387.

20. Bombeccari GP, Guzzi G, Gualini F, et al. Photodynamic therapy to treat periimplantitis. Implant Dent 2013;22:631-8.

21. Albaker AM, ArRejaie AS, Alrabiah M, et al. Effect of photodynamic and laser therapy in the treatment of periimplant mucositis: A systematic review. Photodiagnosis Photodyn Ther 2018;21:147-52.

22. Deeb MA, Alsahhaf A, Mubaraki SA, et al. Clinical and microbiological outcomes of photodynamic and systemic antimicrobial therapy in smokers with peri-

doi: 10.21037/fomm-21-53

Cite this article as: Franco JB, Alves MGO. Effect of antimicrobial photodynamic therapy on the treatment of periimplantitis: narrative review. Front Oral Maxillofac Med 2022;4:13. implant inflammation. Photodiagnosis Photodyn Ther 2020;29:101587.

23. Mizutani K, Aoki A, Coluzzi D, et al. Lasers in minimally invasive periodontal and peri-implant therapy. Periodontol 2000 2016;71:185-212.

24. Fraga RS, Antunes LAA, Fontes KBFDC, et al. Is Antimicrobial Photodynamic Therapy Effective for Microbial Load Reduction in Peri-implantitis Treatment? A Systematic Review and Meta-Analysis. Photochem Photobiol 2018;94:752-9.

25. Cadore UB, Reis MBL, Martins SHL, et al. Multiple sessions of antimicrobial photodynamic therapy associated with surgical periodontal treatment in patients with chronic periodontitis. J Periodontol 2019;90:339-49.

26. Zhao Y, Pu R, Qian Y, et al. Antimicrobial photodynamic therapy versus antibiotics as an adjunct in the treatment of periodontitis and peri-implantitis: A systematic review and meta-analysis. Photodiagnosis Photodyn Ther 2021;34:102231. 